\title{
Impact of Selected Socio-Economic Variables on the Adoption of the Organic cultivation in the State of Nagaland and Manipur
}

\author{
Th. Motilal Singh and Amod Sharma* \\ Department of Agricultural Economics, School of Agricultural Sciences and Rural \\ Development, Nagaland University, Medziphema Campus, Nagaland-797106, India \\ *Corresponding author
}

\begin{abstract}
A B S T R A C T
\section{Keywords}

Socio-economic, profile, Impact, Economic, Management

Article Info

Accepted:

22 June 2020

Available Online:

10 July 2020

In India, agriculture is important occupation of which 52.00 per cent of the people depend for their livelihood. Although agriculture dominates the primary sector however it has not reached its potential level, since most of the farmers use traditional technology, slow adoption of modern and proven technologies which impaired productivity and results in lower standard living of the framers in the region. In flip side the intensification of agriculture in recent decades made the agricultural sector unsustainable due to overexploitation of groundwater and land degradation because of non-judicious of fertilizers. To meet the objectives of the proposed study, both primary as well as secondary have been collected. The primary data and other relevant information of the proposed study has been collected by adopting personal interview method from the selected farm households in the study area for agricultural year 2016 to 2018.
\end{abstract}

\section{Introduction}

The world's population is projected to reach 8.50 billion by 2030, 9.7 billion by 2050 and exceed 11 billion in 2100, with India expected to surpass China as the most populous around seven years from now and Nigeria overtaking the United States to become the world's third largest country around 35 years from now, according to a new United Nations report released today (UNO, 2015). According to the report of "Future of Food and Agriculture, Trends and Challenges; 22 February, 2017FAO-United nation" major transformation in agricultural systems, rural economics and natural resource management will be needed if we are to meet the multiple challenges before us and realize the full potential of food and agriculture to ensure a secure and healthy future for all people and the entire planet. High-input, resource-intensive farming system, which has caused massive deforestation, water scarcities, soil depletion and high levels of green-house emission cannot deliver sustainable food and agricultural production, adds the report.

Village-Community System of farming exists in different parts of the world becomes an indispensable part if the concept of sustainability arises. Different Taboos or culture and practices have been maintain in 
certain agricultural heritage site of the world and this heritage becomes the basis for their social, economic life since time immoral (Small Holders farming Mechanism).

Back to our nation, India's agricultural scenario was also facing the problems of population growth, post Independence political dilemma across the union of India and the great Famine during the two decades had led to the rise of Green Revolution in the 60s. With these, agricultural modernization emerged and the India's food grains production figure became almost the doubled.

Agriculture infrastructural development had given priorities during the India's Five Years Plan and resulted in a positive impact on the production scenario of the nation till she witnessed an irregular and sharp declined in the production and productivity level of some major food crops. Eminent Scientists, Experts, Policy makers \& Planners and different Stakeholders reveals that the country un-sustainability like scenario in the entire agricultural system may be attributed by many factors such as injudicious use of synthetic inorganic inputs in the production processes, deterioration of natural resources and society-triggered climate change phenomena.

It is also estimated that the India's population will reach 1.47 billion by 2030. Again with the advancement of Health Sciences, Indian consumers are realizing on the healthy food for the future perspectives. The present Government of India also emphasises on the Doubling of Farm Income through various technologies intervention on sustainable approach by 2022 . Bringing or balancing the entire scenario on the sustainable basis requires integrated and cummulative efforts of different Stakeholders from Top to Bottom or Bottom to Top approach through indebt study and understanding of the present existing systems and their nature of resource management patterns.

\section{Materials and Methods}

The present study has been carried out in Manipur and Nagaland both state in consultation with the organizations and the line-departments working in the field of Organic farming at the first and secondly the feasibility of the researcher. A multi-stagerandom sampling technique has been used for the selection of sample units. Both purposive and cluster sampling method have been used for the selection districts, blocks and surveyed of the sample sizes.

In the first stage of sampling, Dimapur and Kohima both districts from Nagaland and Senapati and Thoubal districts from Manipur were selected purposively due to popularity and production of major horticultural crops. In the second stage block having highest acreage and production of major horticultural crops under the selected district has been selected with the help of District Agriculture Department and other reputed institutes. Kohima and Medziphema from Nagaland and Thoubal \& Mao-Maram blocks from Manipur were purposively. In the third stage, a list of villages under the selected block was prepared with the help of Block Development Officer / District Agriculture Department and ICAR institutes. Accordingly, Medziphema and Jakhama from Nagaland and Phikomai; Kalinamei and Waithou Chiru were selected for the study. In the fourth stage of sampling plan, with the help of the selected villages, authority (Headman) and KVKs institutes, the farmers who cultivate pineapple and potato were analysed and from these villages, 300 farmers (150 respondent farmers from Manipur and 150 respondent farmers from Nagaland) were selected for each crop (i. e; 75 farmers/ crop) for the data collection of the above crops. From the prepared farmers list, 
by adopting stratified random sampling, proportional allocation and cluster sampling techniques, the respondent farmers were drawn for collection of information using pretested schedule.

The categorizations of household farmers into marginal, small and medium group were done on the basis of their operational land holdings as follows:

$\begin{array}{ll}\text { Marginal } & : \text { Less than ha } \\ \text { Small } & : 1.01 \text { to } 2 \text { ha } \\ \text { Medium } & : 2.01 \& \text { above. }\end{array}$

\section{Results and Discussion}

The socio-economic variable is also important parameters that determine the development of the farmers and farm. This is because, the enterprise vary in their level and types of resources requirements like age, education, labour, land, capital and the managerial skill which is indirectly related to their level of education also effect the farm income and nature of farm business. Hence a discussion on the socio economic variables of the sample farmer of vegetables growers such as level of education, occupational pattern, land resources and its utilization, available labour force etc;

Table 1 reveals the overall (or as total) it was recorded highest with 59.65 per cent for the age up to 12 years and it was found to be minimum with 2.65 per cent for the 60 years and above group, whereas for the Nagaland state it was recorded highest with 59.28 per cent are in the age up to 12 years and it was found to be minimum with 3.27 per cent for the 60 years and above group, while in the Dimapur district it was recorded highest with 61.68 per cent are in the age up to 12 years and it was found to be minimum with 4.67 per cent for the 60 years and above group, while in Kohima district it is having same trends with the maximum of 58.02 per cent for the age up to 12 years and it was minimum with 2.54 per cent for 60 years and above age groups. Even for the Manipur state it was recorded highest with 60.00 per cent are in the age up to 12 years and it was found to be minimum with 2.06 per cent for the 60 years and above group, while in the Thombal district it was recorded highest with 63.06 per cent are in the age up to 12 years and it was found to be minimum with 3.00 per cent for the 60 years and above group, while in Senapati district it is having same trends with the maximum of 58.68 per cent for the age up to 12 years and it was minimum with 1.66 per cent for 60 years and above age groups, respectively.

Table 2 reveals the gender overall (or as total) of farm households, it was recorded highest with 50.67 per cent for the male and it was found to be minimum with 49.33 per cent for the female, while for the Nagaland state it was recorded highest with 50.59 per cent are female and it was found to be minimum with 49.41 per cent for the male flock, while in the Dimapur district it was recorded highest with 51.26 per cent are the male and it was found minimum with 48.74 per cent for female flock group, whereas in Kohima district it is having same overall trend of Nagaland state with the maximum of 51.62 per cent for female group and it was minimum with 48.38 per cent for male cadre.

Even for the Manipur state it was recorded highest with 51.84 per cent are of male and it was found to be minimum with 48.16 per cent for female flock, while in the Thombal district it was recorded highest with 53.03 per cent are of male and it was found to be minimum with 46.97 per cent are female group, while in Senapati district it is having same trends with the maximum of 51,29 per cent for male and it was minimum with 48.71 per cent for female flock groups, respectively. 
Table 3 reveals the family members overall (or as total) of farm households, it was recorded highest with 65.33 per cent for 7 to 8 members in the family and it was found to be minimum with 4.67 per cent for having above 10 member in a family, while for the Nagaland state it was recorded highest with 64.00 per cent for 7 to 8 members in the family and it was found to be minimum with 6.00 per cent for having above 10 member in a family, while in the Dimapur district it was recorded highest with 64.00 per cent with 7 to 8 members in the family and it was found to be minimum with 4.00 per cent for having above 10 member in a family, whereas in Kohima district it was the maximum of 64.00 per cent for 7 to 8 members in the family and it was found to be minimum with 7.00 per cent for having above 10 member in a family. Even for the Manipur state it was recorded highest with 66.67 per cent with 7 to 8 members in the family and it was found to be minimum with 3.33 per cent for having above 10 member in a family, while in the Thombal district it was recorded highest with 80.00 per cent with 7 to 8 members in the family and it was found to be zero nil for having above 10 member in a family, while in Senapati district it was maximum of 60.00 per cent having 7 to 8 members in the family and it was found to be minimum with 4.00 per cent for having 5-6 member in a family, respectively.

Table 4 reveals the land holding overall size (or as total) of farm households, it was recorded highest with 58.67 per cent for small farm and it was found minimum with 8.33 per cent for large farm size, while for the Nagaland state it was highest with 62.67 per cent for small holdings and it was minimum with 10.00 per cent for having large size holdings, while in the Dimapur district it was recorded highest with 66.00 per cent with small land holdings and it was found minimum with 6.00 per cent for large holdings of land, whereas in Kohima district it was maximum of 61.00 per cent for small land holdings and it was minimum with 12.00 per cent for large holdings of land, respectively. Even for the Manipur state it was recorded highest with 54.67 per cent with small holdings of land and it was found minimum with 6.67 per cent for large land holdings, whereas in the Thombal district it was highest with 56.00 per cent are of medium farm size groups and it was found minimum with 8.00 per cent with large size land holdings while in Senapati district it was maximum as 64.00 per cent having small land holdings and it was found to be minimum with 6.00 per cent with large size holdings of land, respectively.

Table 5 reveals the farm income on overall size (or as total) of the households, it was recorded highest with 62.67 per cent for medium income groups and it was found minimum on both (high and low income) groups with 18.67 per cent, while for the Nagaland state it was highest with 58.00 per cent for medium income group and it was minimum with 16.67 per cent for low income group, while in the Dimapur district it was highest with 40.00 per cent for high income group and it was minimum with 26.00 per cent for low income group, whereas in Kohima district it was maximum of 70.00 per cent for medium income group and it was minimum with 12.00 per cent for low income group, respectively. Even for the Manipur state it was recorded highest with 67.33 per cent for medium income group and it was minimum with 12.00 per cent for high income group, whereas in the Thombal district it was highest with 50.00 per cent are of medium range income group and it was found minimum with 6.00 per cent with high income group, while in Senapati district it was maximum as 76.00 per cent are of medium income group and it was found to be minimum with 9.00 per cent with low income group, respectively. 
Table.1 Age group of farm households

\begin{tabular}{|c|c|c|c|c|c|c|c|c|c|c|c|c|c|c|c|}
\hline S.No & Category & Dim & $\%$ & Koh & $\%$ & Naga & $\%$ & Thou & $\%$ & Sena & $\%$ & Mani & $\%$ & Total & $\%$ \\
\hline 1. & Up to 12 years & 396 & 61.68 & 709 & 58.02 & 1105 & 59.28 & 379 & 63.06 & 815 & 58.68 & 1194 & 60.00 & 2299 & 59.65 \\
\hline 2. & 13-18 years & 62 & 9.66 & 167 & 13.67 & 229 & 12.29 & 45 & 7.49 & 187 & 13.46 & 232 & 11.66 & 461 & 11.96 \\
\hline 3. & 19-59 years & 154 & 23.99 & 315 & 25.78 & 469 & 25.16 & 159 & 26.46 & 364 & 26.21 & 523 & 26.28 & 992 & 25.74 \\
\hline 4. & $60 \&$ above & 30 & 4.67 & 31 & 2.54 & 61 & 3.27 & 18 & 3.00 & 23 & 1.66 & 41 & 2.06 & 102 & 2.65 \\
\hline & Total & 642 & 100.00 & 1222 & 100.00 & 1864 & 100.00 & 601 & 100.00 & 1389 & 100.00 & 1990 & 100.00 & 3854 & 100.00 \\
\hline
\end{tabular}

Table.2 Gender of farm households

\begin{tabular}{|c|c|c|c|c|c|c|c|c|c|c|c|c|c|c|c|}
\hline S.No & Category & Dim & $\%$ & Koh & $\%$ & Naga & $\%$ & Thou & $\%$ & Sena & $\%$ & Mani & $\%$ & Total & $\%$ \\
\hline 1. & Male & 203 & 51.26 & 343 & 48.38 & 546 & 49.41 & 201 & 53.03 & 418 & 51.29 & 619 & 51.84 & 1165 & 50.67 \\
\hline 2. & Female & 193 & 48.74 & 366 & 51.62 & 559 & 50.59 & 178 & 46.97 & 397 & 48.71 & 575 & 48.16 & 1134 & 49.33 \\
\hline & Total & 396 & 100.00 & 709 & 100.00 & 1105 & 100.00 & 379 & 100.00 & 815 & 100.00 & 1194 & 100.00 & 2299 & 100.00 \\
\hline
\end{tabular}

Table.3 Family members of farm households

\begin{tabular}{|c|c|c|c|c|c|c|c|c|c|c|c|c|c|c|c|}
\hline S.No & Category & Dim & $\%$ & Koh & $\%$ & Naga & $\%$ & Thou & $\%$ & Sena & $\%$ & Mani & $\%$ & Total & $\%$ \\
\hline 1. & 5-6 members & 2 & 4.00 & 16 & 16.00 & 18 & 12.00 & 0 & 0.00 & 4 & 4.00 & 4 & 2.67 & 22 & 7.33 \\
\hline 2. & 7 to 8 members & 32 & 64.00 & 64 & 64.00 & 96 & 64.00 & 40 & 80.00 & 60 & 60.00 & 100 & 66.67 & 196 & 65.33 \\
\hline 3. & 9 to 10 members & 14 & 28.00 & 13 & 13.00 & 27 & 18.00 & 10 & 20.00 & 31 & 31.00 & 41 & 27.33 & 68 & 22.67 \\
\hline 4. & Above 10 members & 2 & 4.00 & 7 & 7.00 & 9 & 6.00 & 0 & 0.00 & 5 & 5.00 & 5 & 3.33 & 14 & 4.67 \\
\hline & Total & 50 & 100.00 & 100 & 100.00 & 150 & 100.00 & 50 & 100.00 & 100 & 100.00 & 150 & 100.00 & 300 & 100.00 \\
\hline
\end{tabular}

Table.4 Land holding size of the farm households

\begin{tabular}{|c|c|c|c|c|c|c|c|c|c|c|c|c|c|c|c|}
\hline S.No & Category & Dim & $\%$ & Koh & $\%$ & Naga & $\%$ & Thou & $\%$ & Sena & $\%$ & Mani & $\%$ & Total & $\%$ \\
\hline 1. & Small & 33 & 66.00 & 61 & 61.00 & 94 & 62.67 & 18 & 36.00 & 64 & 64.00 & 82 & 54.67 & 176 & 58.67 \\
\hline 2. & Medium & 14 & 28.00 & 27 & 27.00 & 41 & 27.33 & 28 & 56.00 & 30 & 30.00 & 58 & 38.67 & 99 & 33.00 \\
\hline 3. & Large & 3 & 6.00 & 12 & 12.00 & 15 & 10.00 & 4 & 8.00 & 6 & 6.00 & 10 & 6.67 & 25 & 8.33 \\
\hline & Total & 50 & 100.00 & 100 & 100.00 & 150 & 100.00 & 50 & 100.00 & 100 & 100.00 & 150 & 100.00 & 300 & 100.00 \\
\hline
\end{tabular}


Table.5 Farm Income of the households

\begin{tabular}{|c|c|c|c|c|c|c|c|c|c|c|c|c|c|c|c|}
\hline S.No & Category & Dim & $\%$ & Koh & $\%$ & Naga & $\%$ & Thou & $\%$ & Sena & $\%$ & Mani & $\%$ & Total & $\%$ \\
\hline 1. & Low & 13 & 26.00 & 12 & 12.00 & 25 & 16.67 & 22 & 44.00 & 9 & 9.00 & 31 & 20.67 & 56 & 18.67 \\
\hline 2. & Medium & 17 & 34.00 & 70 & 70.00 & 87 & 58.00 & 25 & 50.00 & 76 & 76.00 & 101 & 67.33 & 188 & 62.67 \\
\hline 3. & High & 20 & 40.00 & 18 & 18.00 & 38 & 25.33 & 3 & 6.00 & 15 & 15.00 & 18 & 12.00 & 56 & 18.67 \\
\hline \multicolumn{2}{|r|}{ Total } & 50 & 100.00 & 100 & 100.00 & 150 & 100.00 & 50 & 100.00 & 100 & 100.00 & 150 & 100.00 & 300 & 100.00 \\
\hline
\end{tabular}

Table.6 Farm experience of the sample respondents

\begin{tabular}{|c|c|c|c|c|c|c|c|c|c|c|c|c|c|c|c|}
\hline S.No & Category & Dim & $\%$ & Koh & $\%$ & Naga & $\%$ & Thou & $\%$ & Sena & $\%$ & Mani & $\%$ & Total & $\%$ \\
\hline 1. & Low (1-10) & 28 & 56.00 & 62 & 62.00 & 90 & 60.00 & 22 & 44.00 & 65 & 65.00 & 87 & 58.00 & 177 & 59.00 \\
\hline 2. & Medium (11-20) & 15 & 30.00 & 29 & 29.00 & 44 & 29.33 & 24 & 48.00 & 25 & 25.00 & 49 & 32.67 & 93 & 31.00 \\
\hline 3. & High (21-35) & 7 & 14.00 & 9 & 9.00 & 16 & 10.67 & 4 & 8.00 & 10 & 10.00 & 14 & 9.33 & 30 & 10.00 \\
\hline & Total & 50 & 100.00 & 100 & 100.00 & 150 & 100.00 & 50 & 100.00 & 100 & 100.00 & 150 & 100.00 & 300 & 100.00 \\
\hline
\end{tabular}

Table.7 Farmers' debt / loan status of the sample respondents

\begin{tabular}{|c|c|c|c|c|c|c|c|c|c|c|c|c|c|c|c|}
\hline S.No & Category & Dim & $\%$ & Koh & $\%$ & Naga & $\%$ & Thou & $\%$ & Sena & $\%$ & Mani & $\%$ & Total & $\%$ \\
\hline 1. & Yes & 18 & 36.00 & 19 & 19.00 & 37 & 24.67 & 3 & 6.00 & 22 & 22.00 & 25 & 16.67 & 62 & 20.67 \\
\hline 2. & No & 32 & 64.00 & 81 & 81.00 & 113 & 75.33 & 47 & 94.00 & 78 & 78.00 & 125 & 83.33 & 238 & 79.33 \\
\hline & Total & 50 & 100.00 & 100 & 100.00 & 150 & 100.00 & 50 & 100.00 & 100 & 100.00 & 150 & 100.00 & 300 & 100.00 \\
\hline
\end{tabular}

Table.8 Source of knowledge of the sample respondents

\begin{tabular}{|c|c|c|c|c|c|c|c|c|c|c|c|c|c|c|c|}
\hline S.No & Category & Dim & $\%$ & Koh & $\%$ & Naga & $\%$ & Thou & $\%$ & Sena & $\%$ & Mani & $\%$ & Total & $\%$ \\
\hline 1. & Low & 28 & 56.00 & 36 & 36.00 & 64 & 42.67 & 12 & 24.00 & 42 & 42.00 & 54 & 36.00 & 118 & 39.33 \\
\hline 2. & Medium & 16 & 32.00 & 52 & 52.00 & 68 & 45.33 & 17 & 34.00 & 50 & 50.00 & 67 & 44.67 & 135 & 45.00 \\
\hline 3. & High & 6 & 12.00 & 12 & 12.00 & 18 & 12.00 & 21 & 42.00 & 8 & 8.00 & 29 & 19.33 & 47 & 15.67 \\
\hline \multicolumn{2}{|r|}{ Total } & 50 & 100.00 & 100 & 100.00 & 150 & 100.00 & 50 & 100.00 & 100 & 100.00 & 150 & 100.00 & 300 & 100.00 \\
\hline
\end{tabular}


Table.9 Head of the family education level of the sample respondents

\begin{tabular}{|c|c|c|c|c|c|c|c|c|c|c|c|c|c|c|c|}
\hline S.No & Category & Dim & $\%$ & Koh & $\%$ & Naga & $\%$ & Thou & $\%$ & Sena & $\%$ & Mani & $\%$ & Total & $\%$ \\
\hline 1. & Illiterate & 3 & 6.00 & 18 & 18.00 & 21 & 14.00 & 11 & 22.00 & 19 & 19.00 & 30 & 20.00 & 51 & 17.00 \\
\hline 2. & Up to Primary & 14 & 28.00 & 32 & 32.00 & 46 & 30.67 & 14 & 28.00 & 30 & 30.00 & 44 & 29.33 & 90 & 30.00 \\
\hline 3. & Pre-Matric & 17 & 34.00 & 24 & 24.00 & 41 & 27.33 & 13 & 26.00 & 25 & 25.00 & 38 & 25.33 & 79 & 26.33 \\
\hline 4. & Matric & 13 & 26.00 & 7 & 7.00 & 20 & 13.33 & 12 & 24.00 & 20 & 20.00 & 32 & 21.33 & 52 & 17.33 \\
\hline 5. & Intermediate & 2 & 4.00 & 10 & 10.00 & 12 & 8.00 & 0 & 0.00 & 5 & 5.00 & 5 & 3.33 & 17 & 5.67 \\
\hline 6. & Graduate $\&$ above & 1 & 2.00 & 9 & 9.00 & 10 & 6.67 & 0 & 0.00 & 1 & 1.00 & 1 & 0.67 & 11 & 3.67 \\
\hline & Total & 50 & 100.00 & 100 & 100.00 & 150 & 100.00 & 50 & 100.00 & 100 & 100.00 & 150 & 100.00 & 300 & 100.00 \\
\hline
\end{tabular}

Table.10 Farmers' network of the sample respondents

\begin{tabular}{|c|c|c|c|c|c|c|c|c|c|c|c|c|c|c|c|}
\hline S.No & Category & Dim & $\%$ & Koh & $\%$ & Naga & $\%$ & Thou & $\%$ & Sena & $\%$ & Mani & $\%$ & Total & $\%$ \\
\hline 1. & Low & 4 & 8.00 & 41 & 41.00 & 45 & 30.00 & 12 & 24.00 & 37 & 37.00 & 49 & 32.67 & 94 & 31.33 \\
\hline 2. & Medium & 20 & 40.00 & 48 & 48.00 & 68 & 45.33 & 31 & 62.00 & 59 & 59.00 & 90 & 60.00 & 158 & 52.67 \\
\hline 3. & High & 26 & 52.00 & 11 & 11.00 & 37 & 24.67 & 7 & 14.00 & 4 & 4.00 & 11 & 7.33 & 48 & 16.00 \\
\hline & Total & 50 & 100.00 & 100 & 100.00 & 150 & 100.00 & 50 & 100.00 & 100 & 100.00 & 150 & 100.00 & 300 & 100.00 \\
\hline
\end{tabular}

Table.11 Frequency of the extension visits on the sample respondents farm

\begin{tabular}{|c|c|c|c|c|c|c|c|c|c|c|c|c|c|c|c|}
\hline S.No & Category & Dim & $\%$ & Koh & $\%$ & Naga & $\%$ & Thou & $\%$ & Sena & $\%$ & Mani & $\%$ & Total & $\%$ \\
\hline 1. & Low & 12 & 24.00 & 82 & 82.00 & 94 & 62.67 & 29 & 58.00 & 73 & 73.00 & 102 & 68.00 & 196 & 65.33 \\
\hline 2. & Medium & 23 & 46.00 & 13 & 13.00 & 36 & 24.00 & 17 & 34.00 & 19 & 19.00 & 36 & 24.00 & 72 & 24.00 \\
\hline 3. & High & 15 & 30.00 & 5 & 5.00 & 20 & 13.33 & 4 & 8.00 & 8 & 8.00 & 12 & 8.00 & 32 & 10.67 \\
\hline \multicolumn{2}{|r|}{ Total } & 50 & 100.00 & 100 & 100.00 & 150 & 100.00 & 50 & 100.00 & 100 & 100.00 & 150 & 100.00 & 300 & 100.00 \\
\hline
\end{tabular}


Table.12 Farmers' training in organic cultivation techniques on the sample respondents farm

\begin{tabular}{|c|l|c|c|c|c|c|c|c|c|c|c|c|c|c|c|}
\hline S.No & Category & Dim & \% & Koh & \% & Naga & \% & Thou & \% & Sena & \% & Mani & \% & Total & \% \\
\hline 1. & Low & 12 & 24.00 & 19 & 19.00 & 31 & 20.67 & 29 & 58.00 & 65 & 65.00 & 94 & 62.67 & 125 & 41.67 \\
\hline 2. & Medium & 22 & 44.00 & 73 & 73.00 & 95 & 63.33 & 17 & 34.00 & 27 & 27.00 & 44 & 29.33 & 139 & 46.33 \\
\hline 3. & High & 16 & 32.00 & 8 & 8.00 & 24 & 16.00 & 4 & 8.00 & 8 & 8.00 & 12 & 8.00 & 36 & 12.00 \\
\hline & Total & 50 & 100.00 & 100 & 100.00 & 150 & 100.00 & 50 & 100.00 & 100 & 100.00 & 150 & 100.00 & 300 & 100.00 \\
\hline
\end{tabular}

Table.13 Number of labours work-force of the sample respondents

\begin{tabular}{|c|c|c|c|c|c|c|c|c|c|c|c|c|c|c|c|}
\hline S.No & Category & Dim & $\%$ & Koh & $\%$ & Naga & $\%$ & Thou & $\%$ & Sena & $\%$ & Mani & $\%$ & Total & $\%$ \\
\hline 1. & Only 1 & 0 & 0.00 & 1 & 2.00 & 1 & 0.67 & 0 & 0.00 & 0 & 0.00 & 0 & 0.00 & 1 & 0.33 \\
\hline 2. & 2-3 labour & 59 & 59.00 & 20 & 40.00 & 79 & 52.67 & 24 & 48.00 & 41 & 41.00 & 65 & 43.33 & 144 & 48.00 \\
\hline 3. & 4-5 labour & 41 & 41.00 & 27 & 54.00 & 68 & 45.33 & 25 & 50.00 & 54 & 54.00 & 79 & 52.67 & 147 & 49.00 \\
\hline 4. & $6 \&$ above & 0 & 0.00 & 2 & 4.00 & 2 & 1.33 & 1 & 2.00 & 5 & 5.00 & 6 & 4.00 & 8 & 2.67 \\
\hline & Total & 100 & 100.00 & 50 & 100.00 & 150 & 100.00 & 50 & 100.00 & 100 & 100.00 & 150 & 100.00 & 300 & 100.00 \\
\hline
\end{tabular}

Table.14 Education level of farm households

\begin{tabular}{|c|c|c|c|c|c|c|c|c|c|c|c|c|c|c|c|}
\hline S.No & Category & Dim & $\%$ & Koh & $\%$ & Naga & $\%$ & Thou & $\%$ & Sena & $\%$ & Mani & $\%$ & Total & $\%$ \\
\hline 1. & Illiterate & 65 & 16.41 & 86 & 12.13 & 151 & 13.67 & 36 & 9.50 & 102 & 12.52 & 138 & 11.56 & 289 & 12.57 \\
\hline 2. & Up to Primary & 109 & 27.53 & 162 & 22.85 & 271 & 24.52 & 138 & 36.41 & 198 & 24.29 & 336 & 28.14 & 607 & 26.40 \\
\hline 3. & Pre-matric & 155 & 39.14 & 261 & 36.81 & 416 & 37.65 & 152 & 40.11 & 302 & 37.06 & 454 & 38.02 & 870 & 37.84 \\
\hline 4. & Matric & 40 & 10.10 & 92 & 12.98 & 132 & 11.95 & 35 & 9.23 & 126 & 15.46 & 161 & 13.48 & 293 & 12.74 \\
\hline 5. & Intermediate & 23 & 5.81 & 87 & 12.27 & 110 & 9.95 & 15 & 3.96 & 72 & 8.83 & 87 & 7.29 & 197 & 8.57 \\
\hline 6. & Graduate \& above & 4 & 1.01 & 21 & 2.96 & 25 & 2.26 & 3 & 0.79 & 15 & 1.84 & 18 & 1.51 & 43 & 1.87 \\
\hline & Total & 396 & 100.00 & 709 & 100.00 & 1105 & 100.00 & 379 & 100.00 & 815 & 100.00 & 1194 & 100.00 & 2299 & 100.00 \\
\hline
\end{tabular}


Table 6 reveals the farm experience on overall size (or as total) of the sample respondents and it was recorded highest with 59.00 per cent for low experience and it was found minimum with 10.00 per cent for high farm experiences, while for the Nagaland state it was highest with 60.00 per cent for low experience and it was minimum with 10.67 per cent for high farm experiences, Even for the Manipur state it was recorded highest with 58.00 per cent for low experiences and it was minimum with 9.33 per cent for high farm experiences, respectively.

Table 7 reveals the Farmers' debt / loan status of the sample respondents on overall size (or as total) of the sample respondents that 79.33 per cent as recorded highest has not taken any types of debt or loan, while 20.67 per cent have taken debt / loan, while for the Nagaland state it was highest with 75.33 per cent for not taken any types of debt or loan, while 24.67 per cent have taken debt / loan, Even for the Manipur state it was recorded that 83.33 per cent have not taken any types of debt or loan, while 16.67 per cent have ken debt / loan, respectively.

Table 8 reveals the source of knowledge of the sample respondents on overall size (or as total) of the sample respondents that 45.00 per cent was recorded highest on medium source of knowledge and minimum with 15.67 per cent were in the high source of knowledge, while for the Nagaland state it was highest with 45.33 per cent on medium source of knowledge and it was minimum with 12.00 per cent with high source of knowledge. Even for the Manipur state it was highest with 44.67 per cent on medium source of knowledge and it was minimum with 19.33 per cent with high source of knowledge, respectively.

Table 9 reveals the head of the family education level of the sample respondents on overall size (or as total) of the sample respondents that 30.00 per cent was recorded highest as up to primary level of education and minimum with 3.67 per cent were graduate and above qualification as head of the family members, while for the Nagaland state it was highest with 30.67 per cent was recorded highest as up to primary level of education and minimum with 6.67 per cent were graduate and above qualification as head of the family members. Even for the Manipur state it was highest with 29.33 per cent was recorded highest as up to primary level of education and minimum with 0.67 per cent were graduate and above qualification as head of the family members, respectively.

Table 10 reveals the farmers' network of the sample respondents on overall size (or as total) of the sample respondents that 52.67 per cent was recorded highest as medium network group and minimum with 16.00 per cent were in the high network group, while for the Nagaland state it was highest with 45.33 per cent was recorded highest as medium network group and minimum with 24.67 per cent were in the high network group. Even for the Manipur state it was highest with 60.00 per cent was recorded highest as medium network group and minimum with 7.33 per cent were in the high network group, respectively.

Table 11 reveals the frequency of the extension visits on the sample respondents farm on overall size (or as total) of the sample respondents that 65.33 per cent was recorded highest as low frequency of the extension visits on the farm and minimum with 10.67 per cent were in the high frequency of the extension visits on the farm group, while for the Nagaland state it was highest with 62.67 per cent was recorded highest as low frequency of the extension visits on the farm and minimum with 13.33 per cent were in the high frequency of the extension visits on the farm group. Even for the Manipur state it was 
highest with 68.00 per cent was recorded highest as low frequency of the extension visits on the farm and minimum with 8.00 per cent were in the high frequency of the extension visits on the farm group, respectively.

Table 12 reveals the farmers' training in Organic Cultivation on the sample respondents farm on the sample respondents farm on overall size (or as total) of the sample respondents that 46.33 per cent was recorded highest as medium level of training in organic cultivation techniques on the sample respondents farm and minimum with 12.00 per cent were in the high level of training in organic cultivation techniques on the sample respondents farm, while for the Nagaland state it was highest with 63.33 per cent was recorded highest as medium level of training in organic cultivation techniques on the sample respondents farm and minimum with 16.00 per cent were in the high level of training in organic cultivation techniques on the sample respondents farm. Even for the Manipur state it was highest with 62.67 per cent was recorded highest as low level of training in organic cultivation techniques on the sample respondents farm and minimum with 8.00 per cent were in the high level of training in organic cultivation techniques on the sample respondents farm, respectively.

Table 13 reveals the number of labours workforce on overall size (or as total) of the sample respondents that 49.00 per cent was recorded highest as 4-5 labour engaged on the sample farms and minimum with 0.33 per cent is with only (one) 1 labour on the farm, while for the Nagaland state it was highest with 52.67 per cent was recorded highest as 23 labour engaged on the sample farms and minimum with 0.67 per cent is with only (one) 1 labour on the farm. Even for the Manipur state it was highest with 52.67 per cent was recorded highest as 4-5 labour engaged on the sample farms and it was found (zero) 0.00 per cent labour farm (one) 1 labour on the farm, respectively.

Table 14 reveals the education level of the sample farm households on overall size (or as total) of the sample respondents that 37.84 per cent was recorded highest as up to pre-metric level of education and minimum with 1.87 per cent were graduate and above qualification as sample family members, while for the Nagaland state it was highest with 37.65 per cent was recorded highest as up to pre-metric level of education and minimum with 2.26 per cent were graduate and above qualification as sample of the family members. Even for the Manipur state it was highest with 38.02 per cent was recorded highest as up to pre-metric level of education and minimum with 1.51 per cent were graduate and above qualification as sample of the family members, respectively.

\section{References}

Choudhary, Ramjilal.; Rathore, D.S. and Sharma, Amod. 2017. An Economics Analysis of Production and Marketing of Groundnut in Porbandar District of Gujarat. Economic Affairs. 62(3). September: 547-553.

Das, Kandarpa Kumar. and Sharma, Amod. 2018. Effects on Input Use on Rapeseed and Mustard Production in Nagaon district of Assam. International Journal of Current Microbiology and Applied Sciences. 7(5). May: 629-634.

Dinesh, V. and Sharma, Amod. 2019. A Financial Implication Analysis of different Layer Poultry Farms in Nammakkal district. International Journal of Current Microbiology and Applied Sciences. 8(6): 938-946.

Imlibenla and Sharma, Amod. 2019. Farm Efficiency Measure Analysis of Tea Plantation crop in Mokokchung district of Nagaland. International Journal of Current Microbiology and Applied Sciences. 8(6): 1156-1163.

Jamir, Moanukshi. and Sharma, Amod. 2014. A Sustainable Production and Marketing of 
cucumber crop in the Hilly Zone of Nagaland. Technofame. 3(1). May: 61-66.

Kent, Yuntilo. and Sharma, Amod. 2014. Economic Efficiency on different breeds of Poultry birds under Backyard Management System in Dimapur district of Nagaland. Progressive Agriculture. 14(1): 168-177.

Kulshrestha, R.K. Sharma, V.K. and Sharma, Amod. 2020. A study of Economics of Milk Production in Firozabad district of Western Uttar Pradesh. Plant Achivers. (Accepted for Vol. 20 July 2020).

Sharma, A. and Singh, A.K. 2001. Price Spread of Potato Farmers by Different Farm Size Group in Firozabad District of UP. Andhra Agricultural Journal. 48(1-2): 124-127.

Sharma, A. Chauhan, S. Singh, A.K. Sharma, S.K. and Singh, S.P. 2000. Economics Of Milk Production on Different Farm Size Groups. Dairy Guide. XXI(3-4). July to December: 61-66.

Sharma, Amod. 2005. Economics of Milk Production of Milch Animals on Different Farm Size Groups. The Andhra Agricultural Journal. 52(1-2): 253-257.

Sharma, Amod. 2011. Economic and Constraints of King Chilli Growers in Dimapur District of Nagaland. Journal of Interacademicia. 15(4): 710-719.

Sharma, Amod. 2012. Inter-state Disparities in Socio-economic Development in North East Region of India. Journal of Agricultural Science. 4(9). September: 236243.

Sharma, Amod. 2013. Economics of Production and Marketing of King Chilli in Dimapur District of Nagaland. Indian Journal of Agricultural Marketing. 27(2). May-Aug: 128-141.

Sharma, Amod. 2014. Sustainable economic analysis and extent of satisfaction level of King Chilli growers in Nagaland. Agriculture for Sustainable Development.
2(1). June: 188-191.

Sharma, Amod.; Kichu, Yimkumba. and Chaturvedi, B.K. 2016. Economics and Constraints of Pineapple Cultivation in Dimapur District of Nagaland. The Journal of Rural and Agricultural Research. 16(1). January: 72-75.

Sharma, Amod.; Kichu, Yimkumba. and Sharma, Pradeep. Kumar. 2018. Sustainable economic analysis and constraints faced by the pineapple growers in Nagaland. Progressive Agriculture. 18(1). February: 27-33.

Sharma, Amod.; Singh, J.; Hussain, M.; Tyagi, D.B. and Singh, N.P. 2012. Economics of Saffron (Kesar) Cultivation in Jammu and Kashmir. Environment and Ecology. 30(3C). September: 1070-1075.

Singh, Jaspal. Sharma, Amod., Tyagi, D.B. and Singh, S.P. 2018. Impact of SocioEconomic Variables on the Knowledge and Adoption of the Diversified Agriculture Technologies - A Case Study of DASP adopted villages of Sasni block of Hathras District (UP). International Journal of Current Microbiology and Applied Sciences. 7(5). May: 3095-3102.

Vengoto, Venyo. and Sharma, Amod. 2018. Economic and Constraint of Potato crop in Kohima district of Nagaland. Technoframe. 7(1):75-80.

Yadav, Mukesh. Kumar. and Sharma, Amod. 2019. Effects of socio-economic and occupation on beneficiary and nonbeneficiary Water-shed management catchment areas in the state of Nagaland. International Journal of Current Microbiology and Applied Sciences. 8(9): 1566-1575.

www.uno.org.in.United Nation Sustainable Goal, July 29, 2015.

\section{How to cite this article:}

Motilal Singh, Th. and Amod Sharma. 2020. Impact of Selected Socio-Economic Variables on the Adoption of the Organic cultivation in the State of Nagaland and Manipur. Int.J.Curr.Microbiol.App.Sci. 9(07): 2840-2850. doi: https://doi.org/10.20546/ijcmas.2020.907.336 